\title{
Influência do acúmulo e distribuição de íons sobre a aclimatação de plantas de sorgo e feijão-de-corda, ao estresse salino ${ }^{1}$
}

\author{
Aldo R. Trindade², Claudivan F. de Lacerda ${ }^{2}$, Enéas Gomes Filho ${ }^{3}$, José T. Prisco ${ }^{3}$ \& Marlos A. Bezerra ${ }^{4}$
}

\begin{abstract}
RESUMO
Neste trabalho, estudou-se a influência do acúmulo e distribuição de íons na parte aérea de plantas de feijão-de-corda e de sorgo na aclimatação ao estresse. As plantas foram submetidas a dois tratamentos: ao controle (solução nutritiva sem a adição de $\mathrm{NaCl}$ ) e ao salino (solução nutritiva, contendo $\mathrm{NaCl}$ a $75 \mathrm{mM}$ ). O sorgo mostrou-se mais tolerante ao estresse salino que o feijão-de-corda, notadamente após o 10 o dia de estresse. O feijão-de-corda apresentou maior acúmulo de íons na parte aérea que o sorgo, que se comportou como planta com boa capacidade de exclusão e retenção de íons. O maior acúmulo de íons potencialmente tóxicos nos limbos foliares das plantas de feijão-de-corda, contribuiu para o aumento da suculência. Embora a exclusão ou retenção de íons em plantas de sorgo submetidas a estresse tenha produzido certo grau de desidratação foliar, pareceu tratar-se de um mecanismo de aclimatação ao estresse muito mais eficiente que o aumento da suculência resultante do acúmulo excessivo de íons nos tecidos foliares de plantas de feijão-de-corda.
\end{abstract}

Palavras-chave: salinidade, Vigna unguiculata, Sorghum bicolor, tolerância ao estresse salino

\section{Influence of accumulation and distribution of ions on acclimation of sorghum and cowpea plants to salt stress}

\begin{abstract}
In this paper the influence of accumulation and distribution of ions in plant shoots on acclimation to salt stress of cowpea and sorghum plants was studied. The plants were subjected to two treatments: control (nutrient solution without addition of $\mathrm{NaCl}$ ) and saline (nutrient solution containing $75 \mathrm{mM}$ of $\mathrm{NaCl}$ ). Sorghum showed a higher tolerance to salt stress in comparison to cowpea, mainly after the $10^{\text {th }}$ day of stress. Cowpea showed higher shoot ion accumulation than sorghum, which behaved as a plant with good capacity of ion exclusion. The higher accumulation of potentially toxic ions in cowpea leaves contributed to the increase in leaf succulence. Although the exclusion or retention of ions observed in stressed plants of sorghum had produced a certain degree of leaf dehydration, it seemed to be a much more efficient mechanism of stress acclimation than the excessive accumulation of ions in leaf tissues of cowpea plants.
\end{abstract}

Key words: salinity, Vigna unguiculata, Sorghum bicolor, salt tolerance

${ }^{1}$ Trabalho realizado com o apoio financeiro da FUNCAP e do CNPq

2 Depto. de Engenharia Agrícola/UFC, Campus do Pici, Bloco 804, CEP 60455-970, Fortaleza, CE. Fone: (85) 4008-9763. E-mail: cfeitosa@ufc.br ${ }_{3}^{3}$ Departamento Bioq. e Biol. Molec./UFC, .Fone: (85) 4008-9829. E-mail: egomesf@ufc.br prisco@ultranet.com.br

${ }^{4}$ CNPAT/Embrapa Agroindústria Tropical, Rua Sara Mesquita, 2270, Planalto do Pici, CEP 60511-110, Fortaleza, CE. Fone: (85) 3299 -1895. E-mail: marlos@cnpat.embrapa.br 


\section{INTRODUÇÃO}

A salinidade pode ter sido o fator químico número um de estresse durante a evolução da vida na terra. Os primeiros organismos vivos foram formas de vida marinhas e, mesmo na atualidade, biótipos salinos são colonizados a partir de habitats marinhos e não de habitats de água doce; portanto, logo no início os organismos devem ter desenvolvido mecanismos efetivos para a regulação iônica e para a estabilização de estruturas protoplasmáticas (Larcher, 2000); assim, ao longo da evolução as plantas desenvolveram mecanismos de adaptação a solos salinizados. As plantas que melhor se adaptaram e são nativas de ambientes salinos, são conhecidas como halófitas; por outro lado, as plantas sensíveis à salinidade ou que se adaptaram melhor aos ambientes não salinos, são tidas como glicófitas (Larcher, 2000).

Os efeitos da salinidade no crescimento e desenvolvimento das plantas são assim enumerados: 1) efeito osmótico, posto que uma elevada concentração salina diminui o potencial osmótico do solo, fazendo com que este retenha mais água, disponibilizando-a em menor quantidade para a planta (Gheyi, 2000); 2) efeito tóxico, caracterizado pelo acúmulo de íons específicos na planta. Por exemplo, um excesso de $\mathrm{Na}^{+} \mathrm{e}$ de $\mathrm{Cl}^{-}$no protoplasma ocasiona distúrbios, afetando a fotofosforilação, a cadeia respiratória, a assimilação de nitrogênio e o metabolismo das proteínas. Esses íons começam a inibir a maioria das enzimas envolvidas nesses processos, a uma concentração acima de 100 mM (Larcher, 2000; Munns, 2002); 3) efeito nutricional, no qual o excesso de um íon no solo inibe a absorção de outros íons; por exemplo, quando a concentração de $\mathrm{Na}^{+}$e $\mathrm{Cl}^{-}$no solo é alta, a absorção de nutrientes minerais, especialmente $\mathrm{NO}_{3}{ }^{-}, \mathrm{K}^{+}$e $\mathrm{Ca}^{2+}$ é, quase sempre, reduzida (Marschner, 1995).

De modo geral, as plantas têm duas alternativas para crescer e se reproduzir em ambientes salinos: 1) evitar o acúmulo excessivo de sais, principalmente no tecido fotossintetizante; 2) acumular sal no tecido fotossintetizante, porém de forma compartimentalizada, evitando que os mesmos atinjam os processos e as funções essenciais do vegetal. No caso das halófitas, há compartimentalização eficiente de íons inorgânicos no vacúolo acompanhada do acúmulo de solutos orgânicos compatíveis no citoplasma, os quais mantêm o equilíbrio osmótico entre os compartimentos celulares. Nas glicófitas, o ajustamento osmótico celular também ocorre, porém a compartimentalização dos íons não é tão eficiente como nas halófitas (Hasegawa et al., 2000).

É necessário destacar que, entre as espécies vegetais e dentro de cada espécie, pode-se encontrar variabilidade genética em relação a tolerância à salinidade (Ayers \& Westcot, 1999), a qual pode estar relacionada com diferenças em respostas morfo-fisiológica (Kuiper, 1984; Niu et al., 1995; Moya et al., 1999; Storey, 1995; Lacerda et al., 2003). Espécies como o sorgo [Sorghum bicolor (L) Moench] e o feijão-de-corda [Vigna unguiculata (L.) Walp] são consideradas moderadamente tolerantes (Fageria \& Gheyi, 1997; Ayers \& Westcot, 1999), embora o feijão-de-corda mostre menor valor de salinidade limiar e maior queda na produção com o aumento na salinidade do solo, após atingida a salinidade limiar; além disso, dentro de cada espécie tem-se encontrado genótipos com diferentes graus de tolerância ao estresse salino (Fernandes et al., 1994; Lacerda et al., 2001; Costa et al., 2003) refletindo, provavelmente, as variabilidades nos graus de eficiência dos mecanismos de aclimatação ou adaptação ao excesso de sais no solo.

Do exposto acima, diz-se que a tolerância à salinidade pode estar associada com a maior capacidade de retenção de íons e/ou de compartimentalização intracelular. Na maioria dos casos, no entanto, o maior acúmulo de íons potencialmente tóxicos nos tecidos foliares de glicófitas, parece correlacionar-se com a sensibilidade ao estresse salino, sugerindo que o mecanismo de exclusão de íons indica ser mais eficiente para essas plantas; portanto, objetivou-se, no presente trabalho, avaliar a influência do acúmulo e distribuição de íons na parte aérea sobre a aclimatação de plantas de feijão-de-corda e de sorgo ao estresse salino, na tentativa de se estabelecer relações entre o acúmulo e a distribuição de íons e os mecanismos de tolerância dessas espécies a este fator ambiental de estresse.

\section{MATERIAL E MÉTODOS}

\section{Material vegetal e condições de crescimento}

$\mathrm{O}$ experimento foi conduzido em casa de vegetação do Departamento de Bioquímica e Biologia Molecular, Campus do Pici (UFC), Fortaleza, Ceará, Brasil. Sementes de sorgo forrageiro [Sorghum bicolor (L) Moench] do genótipo CSF 18 e de feijão-de-corda Pitiúba [Vigna unguiculata (L.) Walp] foram selecionadas quanto ao tamanho e forma, lavadas em água corrente e semeadas em recipientes contendo vermiculita agrícola saturada com água destilada.

Sete dias após a semeadura, as plântulas foram selecionadas com base no critério de uniformidade e transferidas para bandejas de $10 \mathrm{~L}$, contendo solução nutritiva de Clark completa (com o dobro da concentração de fósforo) continuamente aerada, $\mathrm{pH}$ 5,5, em casa de vegetação. O volume da solução foi sustentado pela adição diária de água destilada. Passados sete dias de aclimatação a essas condições, as plântulas foram transferidas para vasos de três litros (uma planta por vaso) contendo a mesma solução, e sob as mesmas condições. Utilizaram-se dois tratamentos, sendo um controle (solução nutritiva sem $\mathrm{NaCl}$ ) e outro salino (solução nutritiva com $\mathrm{NaCl}$ a $75 \mathrm{mM}$ ), este último obtido pela adição parcelada de $\mathrm{NaCl}$ (25 mM a cada $48 \mathrm{~h}$ ).

As soluções nutritivas foram trocadas a cada cinco dias sendo o pH diariamente monitorado e, quando necessário, ajustado para 5,5, com $\mathrm{NaOH}$ ou $\mathrm{HCl} \mathrm{0,1} \mathrm{M.} \mathrm{Os} \mathrm{valores} \mathrm{de}$ temperatura média e de umidade relativa média no interior da casa de vegetação, durante o período experimental, foram de $29,5{ }^{\circ} \mathrm{C}$ e $71,5 \%$, respectivamente.

\section{Análise das respostas morfo-fisiológicas}

Nos dias zero, 5, 10, 15 e 20 do início da adição do $\mathrm{NaCl}$, realizaram-se coletas medindo-se a produção de matéria fresca e a área foliar (LI-3000, Área Meter, Li-Cor., Inc., Lincoln, 
e,Nebraska, USA); em seguida, o material foi posto para secar, em estufa com circulação forçada de ar a $60{ }^{\circ} \mathrm{C}$, para obtenção da matéria seca das raízes, dos caules (caules + pecíolos, para feijão e colmos + bainhas, para sorgo) e dos limbos foliares. Com essas medidas, calcularam-se a massa específica foliar (massa seca foliar/área foliar) e a suculência foliar [(massa fresca - massa seca)/área foliar], conforme proposto por Mantovani (1999).

\section{Acúmulo e distribuição de íons na parte aérea}

O material vegetal seco foi finamente moído e utilizado para determinação dos elementos minerais. Os materiais resultantes da moagem dos limbos e dos caules + pecíolos (feijão-decorda) ou colmos + bainhas (sorgo), foram empregados para determinação dos teores de $\mathrm{Na}^{+}, \mathrm{K}^{+}$e $\mathrm{Cl}^{-}$, em que o extrato foi obtido pela mistura de $50 \mathrm{mg}$ de matéria seca, com $10 \mathrm{~mL}$ de água desmineralizada, após agitação durante uma hora e posterior filtração em papel de filtro. Os teores da $\mathrm{Na}^{+}$e $\mathrm{K}^{+}$foram determinados por fotometria de chama (Malavolta et al., 1989) e o do $\mathrm{Cl}^{-}$por espectrofotometria (Gaines et al., 1984). Os teores foram expressos na base de matéria seca. Com esses dados e com os conteúdos de água dos tecidos, foram estimadas as concentrações na base de água tissular.

\section{Delineamento e análises estatísticas}

O experimento foi montado seguindo um delineamento inteiramente casualizado, em esquema fatorial ( $2 \times 2 \times 5)$ e se utilizando-se quatro repetições. Os resultados foram submetidos à análise de variância (ANOVA) e de regressão, através do programa SAEG (Sistema de Análises Estatísticas e Genéticas) desenvolvido pela Universidade Federal de Viçosa.

\section{RESULTADOS E DISCUSSÃO}

Os resultados da análise de variância mostram que praticamente todas as respostas estudadas foram influenciadas pela salinidade, pelo tempo de estresse e pela espécie vegetal (Tabela 1). Também foram verificados efeitos significativos para as interações, indicando que as variáveis se comportaram de forma diferente em relação aos três fatores analisados. Particularmente, a interação espécie x tratamento foi significativa para todas as variáveis testadas.

A matéria seca total das plantas de feijão-de-corda e de sorgo em função do tempo, está representada respectivamente nas Figuras $1 \mathrm{~A}$ e 1B, cujas análises revela que o feijão-decorda sob tratamento salino começou a se diferenciar do controle a partir do 10o dia, apresentando redução na matéria seca até o final do experimento. No caso do sorgo, esta diferença começou a se definir, também, a partir do 10ํ dia, porém em nível bem menor que aquele apresentado pelo feijão-de-corda. Referidos resultados estão de acordo com os obtidos na literatura os quais mostram que, embora as duas espécies sejam classificadas como moderadamente tolerantes, o feijãode-corda mostra maior queda no crescimento quando os níveis de salinidade do solo aumentam (Ayers \& Westcot, 1999).

A concentração de íons potencialmente tóxicos $\left(\mathrm{Na}^{+}+\mathrm{Cl}^{-}\right)$ aumentou, em função do tempo de estresse, mais intensamente em feijão-de-corda que em sorgo, tanto nos caules (dados não mostrados) como nos limbos foliares (Figuras 1C e 1D). É possível que a diferença no acúmulo desses íons nos limbos foliares esteja associado à quantidade de água absorvida durante a aplicação do estresse (Moya et al., 1999; Larcher, 2000), às diferenças na capacidade de exclusão de íons nas raízes e as diferenças na capacidade de retenção desses

Tabela 1. Valores dos quadrados médios e significância estatística para todas as varáveis analisadas, considerando os efeitos isolados de espécie, tratamento e tempo com as respectivas interações

\begin{tabular}{|c|c|c|c|c|c|c|c|}
\hline \multirow[b]{2}{*}{ Espécie } & \multirow[b]{2}{*}{ Tratamento } & \multirow[b]{2}{*}{ Tempo } & \multicolumn{3}{|c|}{ Quadrados Médios } & \multirow[b]{2}{*}{ Esp x Trat x Temp } & \multirow[b]{2}{*}{ Resíduo } \\
\hline & & & Esp $\times$ Trat & Trat $\mathrm{x}$ Temp & Esp x Temp & & \\
\hline \multicolumn{8}{|c|}{ Matéria Seca Total } \\
\hline $9,73^{* \star}$ & $61,94^{\star *}$ & $240,35^{\star \star}$ & $8,47^{\star *}$ & 20,59 ** & $3,94^{* *}$ & $2,62^{\star \star}$ & 0,39 \\
\hline \multicolumn{8}{|c|}{$\mathrm{Na}^{+}+\mathrm{Cl}^{-}$} \\
\hline $8767^{* *}$ & $120795^{\star *}$ & $20541^{\star *}$ & $33504^{* *}$ & $18304^{* *}$ & $2219 * *$ & $4556^{\star *}$ & 153,4 \\
\hline \multicolumn{8}{|c|}{ Relação $\mathrm{Na}^{+} / \mathrm{K}^{+}$} \\
\hline $0,463^{* *}$ & $1,425^{\star *}$ & $0,294^{\star *}$ & $0,395^{\star \star}$ & $0,294^{* *}$ & $0,112^{\star \star}$ & $0,133^{\star *}$ & 0,0016 \\
\hline \multicolumn{8}{|c|}{$\mathrm{Na}^{+}$nos colmos $/ \mathrm{Na}^{+}$nos limbos } \\
\hline $0,188 \mathrm{~ns}$ & $18,66^{\star *}$ & $3,89 * *$ & $0,405^{\star}$ & $3,345^{\star *}$ & $1,350^{\star \star}$ & $2,147^{\star \star}$ & 0,114 \\
\hline \multicolumn{8}{|c|}{$\mathrm{Cl}^{-}$nos colmos/Cl- nos limbos } \\
\hline $2,345^{\star *}$ & $0,052 \mathrm{~ns}$ & $0,849 * *$ & $11,93^{\star \star}$ & $1,11^{* *}$ & 0,549 ** & $1,603^{\text {** }}$ & 0,068 \\
\hline \multicolumn{8}{|c|}{$\mathrm{K}^{+}$nos colmos $/ \mathrm{K}^{+}$nos limbos } \\
\hline $3,881^{* *}$ & $2,946^{* *}$ & $0,553^{\star *}$ & $0,269 * \star$ & $0,338^{* *}$ & $0,220^{\star *}$ & $0,033^{*}$ & 0,010 \\
\hline \multicolumn{8}{|c|}{ Matéria Seca Foliar } \\
\hline $3,32^{\star \star}$ & $9,33^{\star *}$ & $46,52^{\star \star}$ & $1,68^{\star \star *}$ & $3,06^{\star *}$ & $1,68^{\star *}$ & $0,45^{\star \star}$ & 0,10 \\
\hline \multicolumn{8}{|c|}{ Grau de Suculência Foliar } \\
\hline $0,447^{\star *}$ & $0,002 \mathrm{~ns}$ & 0,231 ** & $1,489 * \star$ & $0,009 \mathrm{~ns}$ & $0,385^{\star *}$ & $0,465^{\star \star}$ & 0,015 \\
\hline \multicolumn{8}{|c|}{ Massa Específica Foliar } \\
\hline $0,052^{* *}$ & $0,011^{* *}$ & 0,020 ** & $0,0025^{\star}$ & $0,00095^{\star}$ & $0,015^{\star \star}$ & $0,00040 \mathrm{~ns}$ & 0,00035 \\
\hline
\end{tabular}




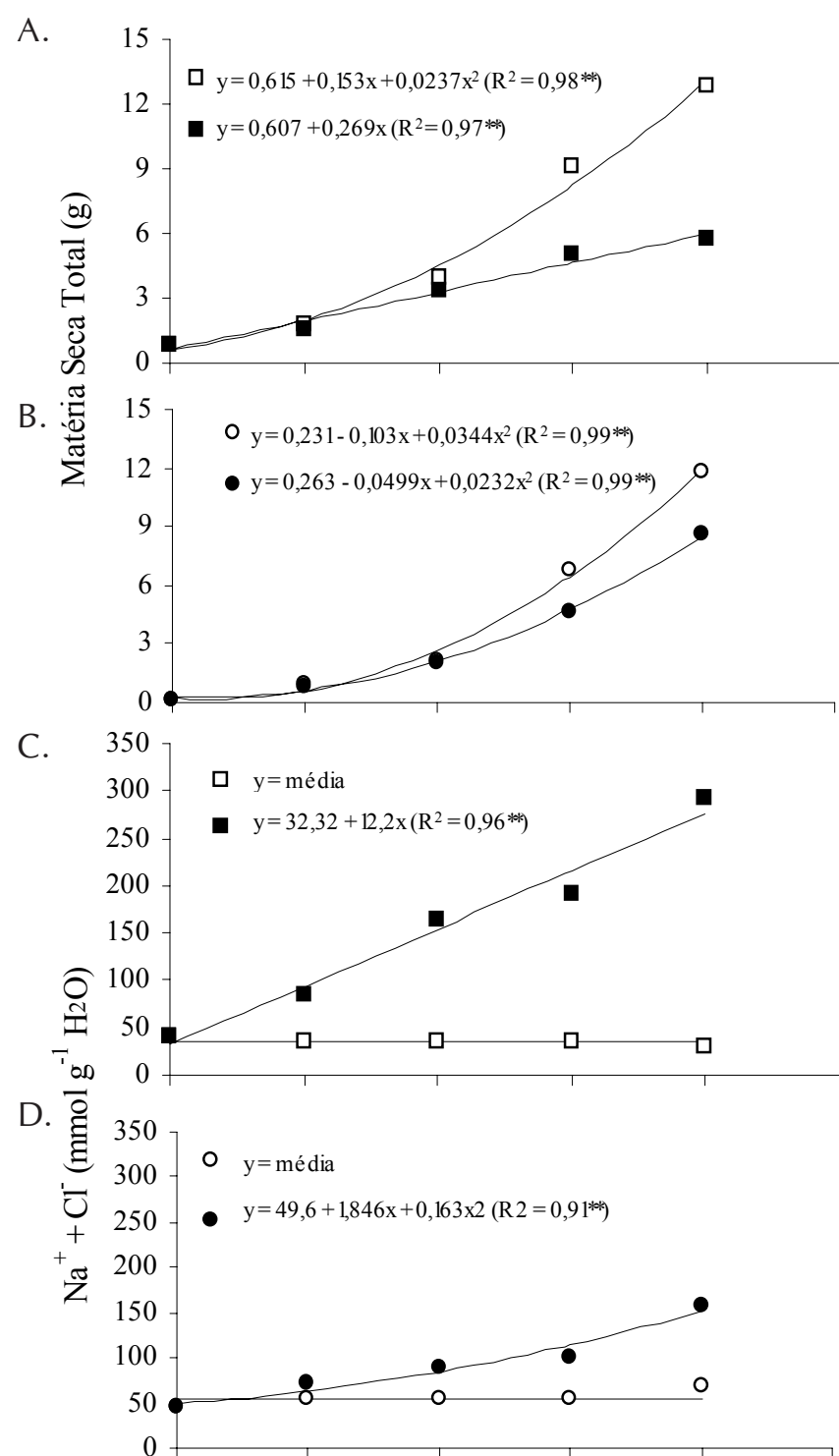

E.

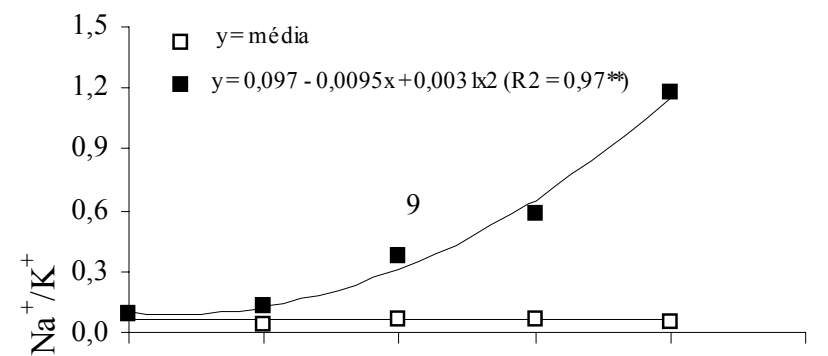

$\mathrm{F}$.

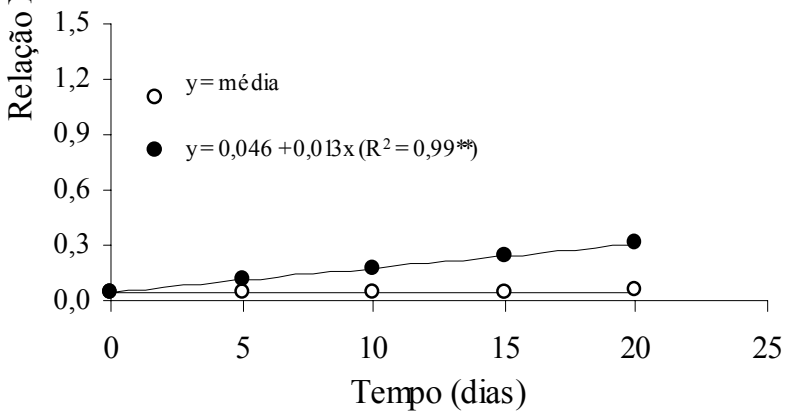

Figura 1. Matéria seca total (raiz + parte aérea), concentração de $\mathrm{Na}^{+}+\mathrm{Cl}^{-} \mathrm{e}$ relação $\mathrm{Na}^{+} / \mathrm{K}^{+}$em limbos foliares de plantas de feijão-de-corda (A, C e E) e de sorgo (B, D e F), em função do tempo de cultivo no tratamento controle (símbolos vazios) e salino (símbolos cheios). ${ }^{* *}$ significativo a $1 \%$ íons nos caules (Boursier \& Lauchli, 1989). De acordo com Munns \& Termaat (1986), quando os teores desses $\mathrm{Na}^{+}$e Clalcançam valores elevados nas folhas maduras, estas iniciam o processo de senescência, reduzindo os teores das clorofilas e a produção de fotoassimilados, afetando o seu fornecimento para as folhas jovens; desta forma, é possível inferir que menor acúmulo desses íons no sorgo pode ter contribuído para a maior tolerância apresentada por esta espécie, em relação ao feijão-de-corda.

A relação $\mathrm{Na}^{+} / \mathrm{K}^{+}$nos limbos foliares foi mais elevada no feijão-de-corda (Figura 1E) sob estresse salino, que no sorgo (Figura 1F), mas a diferença entre essas duas plantas começou a se definir a partir do quinto dia sob estresse. A comparação entre os tratamentos mostrou que tanto para o feijãode-corda quanto para o sorgo, a partir do quinto dia a relação $\mathrm{Na}^{+} / \mathrm{K}^{+}$começou a aumentar na planta estressada, enquanto no controle tendia para uma estabilidade. Esta relação pode ser importante na avaliação do grau de tolerância da planta à salinidade, tendo em vista que o $\mathrm{Na}^{+}$inibe muitas enzimas que requerem potássio (Greenway \& Munns, 1980). Em sorgo, Lacerda et al. (2001) observaram que, sob condições salinas, a relação $\mathrm{Na}^{+} / \mathrm{K}^{+}$foi quase duas vezes maior nos limbos do genótipo sensível em relação ao tolerante, sendo praticamente o mesmo valor encontrado em milho por Hajibagheri et al. (1987).

A Figura 2 mostra a quantidade relativa de íons $\left(\mathrm{Na}^{+}, \mathrm{Cl}^{-} \mathrm{e}\right.$ $\mathrm{K}^{+}$) nos caules e limbos das plantas de feijão-de-corda e de sorgo sob condições normais (controle) e de estresse (salino) em função do tempo de exposição ao estresse. Esta relação é um indicativo da capacidade de retenção do íon no tecido ou órgão; portanto, no presente caso, quanto maior for o aumento da relação em resposta ao estresse, maior também será a retenção do íon no caule. Comparando-se as plantas controle com as estressadas, verifica-se que as duas espécies estudadas mostraram aumentos na capacidade de retenção de $\mathrm{Na}^{+}$nos caules (Figura 2A), em função do tempo de exposição ao estresse, tendo este aumento sido maior nas plantas de feijão-de-corda, durante os primeiros 10 dias de exposição ao estresse. No $15^{\circ}$ dia de estresse não houve diferença entre as duas espécies e, no $20^{\circ}$ dia, observou-se um decréscimo na capacidade de retenção de $\mathrm{Na}^{+}$no caule das plantas de feijão-de-corda, enquanto o sorgo indicou aumento. Notou-se, em feijão-de-corda, um decréscimo na retenção de $\mathrm{Na}^{+}$no caule, com o tempo de exposição ao estresse, ao mesmo tempo em que ocorreu aumento na concentração de íons tóxicos nos limbos foliares (Figura 1C). No caso de sorgo, a capacidade de retenção de $\mathrm{Na}^{+}$no caule, resultante do estresse, permaneceu mais ou menos constante durante todo o período experimental, enquanto ocorreu aumento mínimo no teor de íons tóxicos nos limbos foliares, quando comparado com o feijão-de-corda (Figura 1). Este comportamento sugere que a espécie, além de apresentar maior capacidade de excluir o $\mathrm{Na}^{+}$que chega ao caule (dados não mostrados), exporta também pouco $\mathrm{Na}^{+}$do caule para as folhas evitando, deste modo, o excesso de íons potencialmente tóxicos nos tecidos fotossintetizantes (Lessani \& Marschner, 1978; Salim \& Pit- 
A.

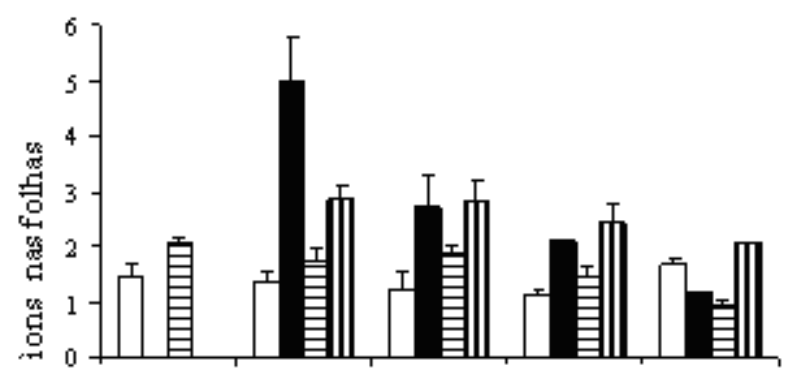

B.

C.
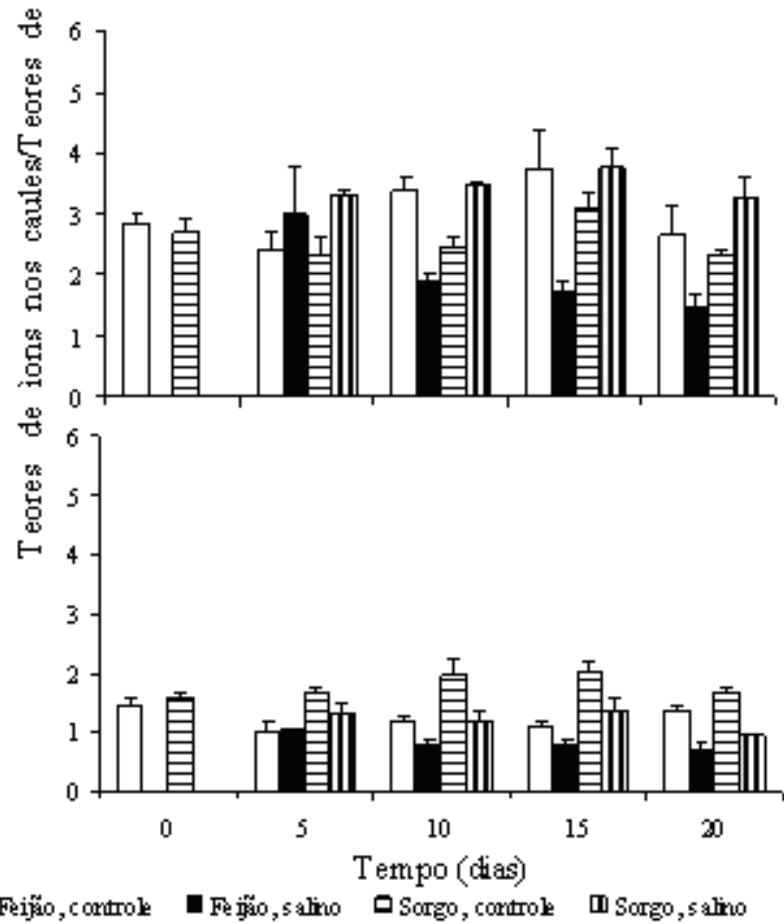

Figura 2. Relação entre os teores de sódio (A), cloreto (B) e potássio (C) nos caules e os teores desses íons nos limbos foliares em plantas de feijão-de-corda e de sorgo, em função do tempo de cultivo, na ausência (controle) ou presença de $\mathrm{NaCl}$ a $75 \mathrm{mM}$ (salino)

man, 1983; Boursier \& Lauchli, 1989; Azevedo Neto \& Tabosa, 2000).

As plantas de sorgo e de feijão-de-corda mostraram comportamentos diferentes em relação à retenção de $\mathrm{Cl}^{-}$no caule (Figura 2B). De modo geral observou-se, em feijão-de-corda, redução na capacidade de retenção de $\mathrm{Cl}^{-}$nos caules das plantas estressadas em comparação com as plantas controle; enquanto isto, nota-se aumento constante no teor de íons tóxicos nos limbos foliares (Figura 1C), sugerindo que esta espécie exporta, do caule para as folhas, a maior parte do $\mathrm{Cl}^{-}$ absorvido, mas o sorgo, pelo contrário, apresentou aumento na capacidade de retenção de $\mathrm{Cl}^{-}$nos caules quando submetido ao estresse salino (Figura 2) e o aumento no teor de íons tóxicos nas folhas foi bem inferior ao observado em feijãode-corda (Figura 1). Esses resultados sugerem melhor eficiência do sorgo em reter os íons potencialmente tóxicos no caule evitando, em conseqüência, sua exportação e acúmulo no limbo foliar, o que pode ter contribuído para a maior tolerância desta espécie ao estresse salino (Boursier \& Lauchli, 1989; Munns, 2002; Lacerda et al., 2003).
A.

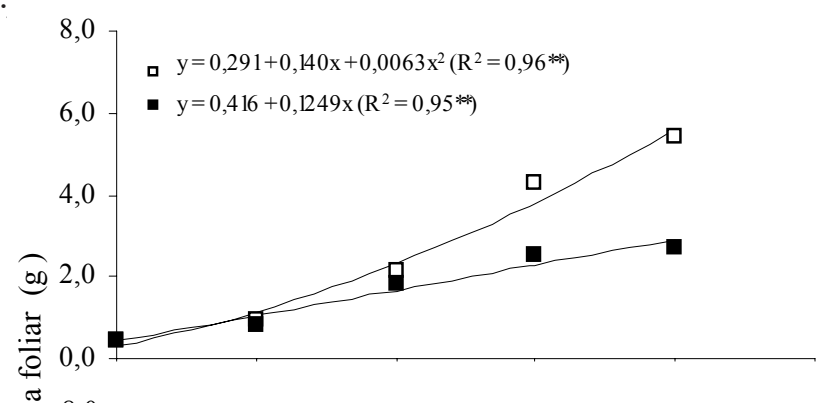

B.
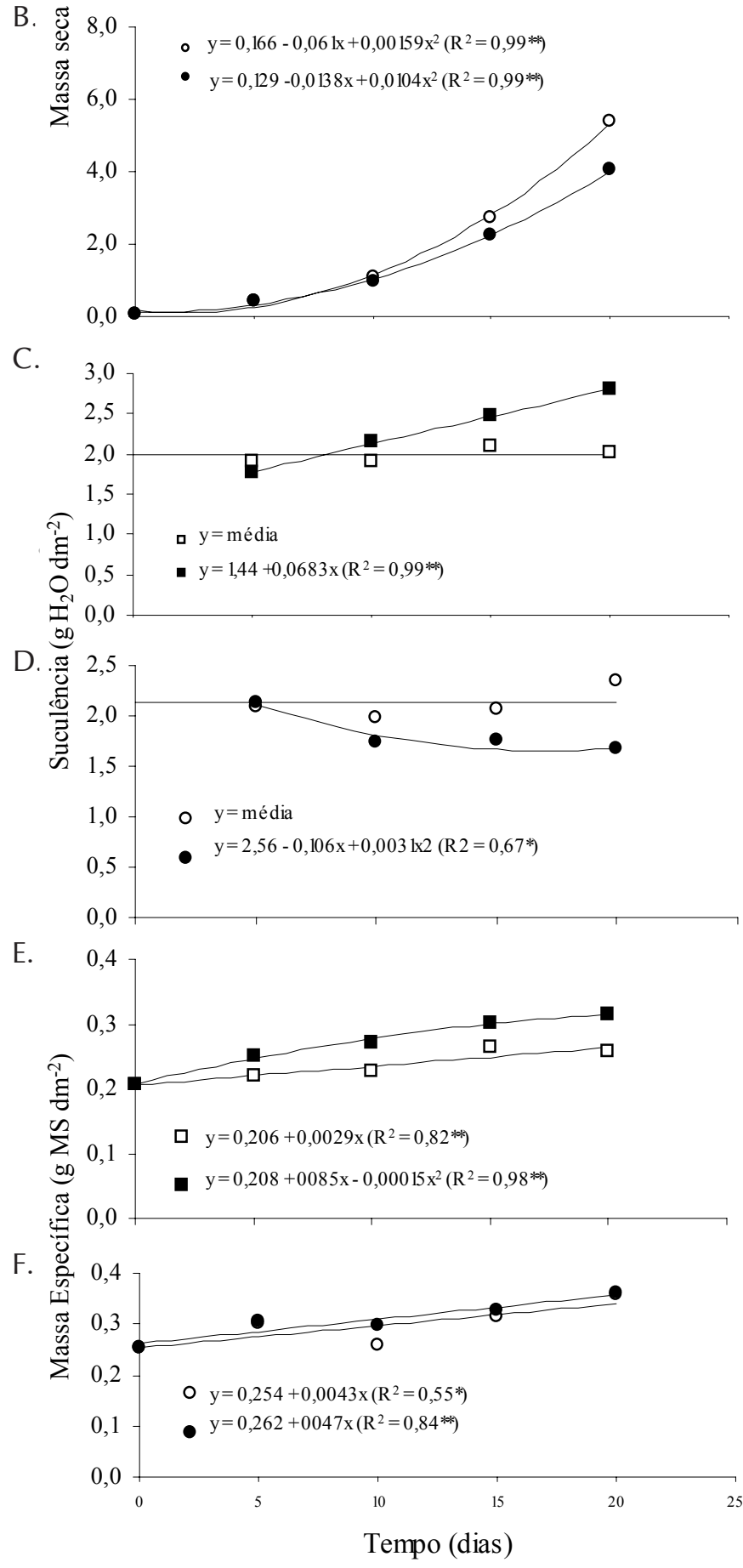

Figura 3. Matéria seca, suculência e massa específica de folhas de plantas de feijão-de-corda ( $A, C$ e E) e de sorgo (B, D e F), em função do tempo de cultivo no tratamento controle (símbolos vazios) e salino (símbolos cheios) *singnificativo a $5 \%, * *$ significativo a $1 \%$ 
O estresse salino provocou redução na retenção de $\mathrm{K}^{+}$nos caules das plantas de feijão-de-corda e de sorgo (Figura 2C). Como a retenção deste íon no caule foi bem menor que as observadas para $\mathrm{Na}^{+}$e $\mathrm{Cl}^{-}$, ressalta-se a existência de mecanismos específicos de absorção de íons nas células dos caules, os quais favorecem a retenção de íons potencialmente tóxicos e o transporte do $\mathrm{K}^{+}$para os tecidos foliares. Entretanto, este transporte foi insuficiente para contrabalançar o excessivo aumento na concentração de $\mathrm{Na}^{+}$nos limbos foliares, como se evidencia pelos valores da relação $\mathrm{Na}^{+} / \mathrm{K}^{+}$nos limbos foliares, ao longo do período experimental (Figuras $1 \mathrm{E}$ e $1 \mathrm{~F}$ ); este fato mais conspícuo em feijão-de-corda que no sorgo sugere, mais uma vez, que a maior tolerância deste último se deve, pelo menos em parte, à exclusão dos íons potencialmente tóxicos dos tecidos fotossintetizantes.

O tratamento salino provocou redução na matéria seca foliar do feijão-de-corda a partir do 10 o dia, tendo esta redução se tornado mais drástica no final do período experimental (Figura 3A); no sorgo, por sua vez, referida redução começou a se definir a partir do 15o dia, de forma menos intensa que aquela verificada no feijão-de-corda (Figura 3B); essa menor redução na matéria seca foliar observada no sorgo pode estar associada ao menor acúmulo de íons tóxicos no limbo (Figuras 1 e 2), o que tem sido sugerido por outros autores (Lacerda et al., 2001; Munns, 2002).

A suculência foliar em feijão-de-corda e em sorgo, em função do tempo de exposição ao estresse, encontra-se respectivamente nas Figuras 3C e 3D, cujas análises mostram, inequivocamente, que o feijão-de-corda apresentou aumento e o sorgo redução, neste parâmetro, com a aplicação do estresse salino, sendo que a suculência do tratamento controle, permaneceu constante ao longo do período experimental. O aumento na suculência foliar em feijão foi observado também por Silva et al. (2003) e por Costa et al. (2003). Este parâmetro possui importantes implicações anatômicas e fisiológicas em plantas submetidas a algum tipo de estresse. A suculência permite a regulação da concentração de sais nos tecidos foliares e depende, diretamente, da absorção, transporte e acúmulo de íons nos tecidos foliares, podendo contribuir para reduzir o efeito dos sais sobre o crescimento da planta, sendo que neste estudo ela foi verificada apenas para o feijãode-corda. Os resultados estão de acordo com os obtidos por outros autores, que mostraram que a suculência é uma resposta comum em folhas de plantas estressadas com sais de cloreto sendo, porém, mais comum em dicotiledôneas (Strogonov, 1964; Zekri, 1991).

As variações na massa específica foliar de feijão-de-corda e de sorgo, em função do tempo de exposição ao estresse, encontram-se respectivamente nas Figuras 3E e 3F. Enquanto em sorgo o estresse salino não afetou a massa específica foliar, em feijão-de-corda observou-se ligeiro aumento, a partir do quinto dia, que foi sendo incrementado até o final do período experimental. Aumento na massa específica foliar de feijãode-corda foi também observado por Silva (1998) e pode estar associado ao aumento da espessura do mesofilo ou ao provável crescimento da espessura das paredes celulares, induzido pelo estresse salino (Prisco, 1980). O incremento da massa específica foliar pelo aumento na espessura do mesofilo, pode favorecer a assimilação de carbono por unidade de área foliar (Boote \& Tollenaar, 1994) e representa um mecanismo de aclimatação ao estresse salino.

\section{CONCLUSÕES}

1. O feijão-de-corda apresentou maior acúmulo de íons, enquanto o sorgo se comportou como planta com boa capacidade de exclusão de íons potencialmente tóxicos, evitando o acúmulo excessivo na parte aérea, notadamente nos limbos foliares.

2. O maior acúmulo de íons potencialmente tóxicos nos limbos foliares de plantas de feijão-de-corda, aumentou a suculência e provocou atenuação na concentração desses íons.

3. Os mecanismos de exclusão e/ou retenção de íons em plantas de sorgo sob condições de estresse salino, embora tenham produzido certo grau de desidratação foliar, indicam ser mais eficientes que o acúmulo excessivo de íons nos tecidos foliares de plantas de feijão-de-corda.

\section{LITERATURA CITADA}

Ayers, R.S.; Westcot, D.W. A qualidade da água na agricultura. Campina Grande, UFPB, 1999. 153p.

Azevedo Neto, A.D.; Tabosa, J.N. Estresse salino em plântulas de milho: Parte II. Distribuição dos macronutrientes catiônicos e suas relações com sódio. Revista Brasileira de Engenharia Agrícola e Ambiental, Campina Grande, v.4, n.2, p.165-171, 2000.

Boote, K.J.; Tollenaar, M. Modeling genetic yield potential. In: Boote, K.J.; Bennett, J.M.; Sinclair, T.R.; Paulsen, G.M. (ed). Physiology and determination of crop yield. Madison: American Society of Agronomy, 1994. cap. 20, p.553-565.

Boursier, P.; Lauchli, A. Mechanisms of chloride partitioning in the leaves of salt-stressed Sorghum bicolor L. Physiologia Plantarum, Copenhagen, v.77, n.4, p.537-544, 1989.

Costa, P.H.A.; Silva, J.V.; Bezerra, M.A.; Enéas-Filho, J.; Prisco, J.T; Gomes-Filho, E. Crescimento e níveis de solutos orgânicos e inorgânicos em cultivares de Vigna unguiculata submetidos à salinidade. Revista Brasileira de Botânica, São Paulo, v.26, n.3, p.289-297, 2003.

Fageria, N.K.; Gheyi, H.R. Melhoramento genético das culturas e seleção de cultivares. In: Simpósio: Manejo e Controle da Salinidade na Agricultura Irrigada. Campina Grande: UFPB, 1997. p.363-383.

Fernandes, M.B.; Castro, J.R.; Fernandes, V.L.B.; Aquino, B.F.; Alves, J.S.; Góis, F.C. Avaliação de cultivares de sorgo forrageiro em solos afetados por sais no Estado do Rio Grande do Norte. Pesquisa Agropecuária Brasileira, Brasília, v.29, n.2, p.255-261, 1994.

Gaines, T.P.; Parker, M.B.; Gascho, G.J. Automated determination of chlorides in soil and plant tissue by sodium nitrate. Agronomy Journal, Madison, v.76, n.3, p.371-374, 1984. 
Gheyi, H.R. Problemas de salinidade na agricultura irrigada. In: Oliveira, T.S.; Assis Jr.,R.N.; Romero, R.E.; Silva, J.R.C. (eds). Agricultura, sustentabilidade e o semi-árido. Fortaleza: Sociedade Brasileira de Ciências do Solo, 2000. p.329346.

Greenway, H.; Munns, R. Mechanisms of sal tolerance in nonhalophytes. Annual Review Plant Physiology, Palo Alto, v.31, p.149-190, 1980.

Hajibagheri, M.A.; Harvey, D..M..R.; Flowers, T.J. Quantitative ion distribution within root cells of salt-sensitive and salt-tolerant maize varieties. New Phytologist, Lancaster, v.105, n.3, p.367-379, 1987.

Hasegawa, P.; Bressan, R.A.; Zhu, J.K.; Bohnert, J. Plant cellular and molecular responses to high salinity. Annual Review Plant Physiology and Plant Molecular Biology, Palo Alto, v.51, p.463-499, 2000.

Kuiper, P.J.C. Functioning of plants cells membranes under saline conditions: membrane lipid composition and ATPases. In: Staples, R.C.; Toenniessen, G.H. (eds.) Salinity tolerance in plants. New York: Willey, 1984. p.77-91.

Lacerda, C.F.; Cambraia, J.; Cano, M.A.O.; Ruiz, H.A. Plant growth and solute accumulation and distribution in two sorghum genotypes, under $\mathrm{NaCl}$ stress. Revista Brasileria de Fisiologia Vegetal, Londrina, v.13, n.3, p.270-284, 2001.

Lacerda, C.F.; Cambraia, J.; Cano, M.A.O.; Ruiz, H.A.; Prisco, J.T. Solute accumulation and distribution during shoot and leaf development in two sorghum genotypes under salt stress. Environmental and Experimental Botany, Paris, v.49, n.2, p.107-120, 2003.

Larcher, W. Ecofisiologia vegetal. São Carlos: Ed. Rima Artes e Textos, 2000. 531p.

Lessani, H.; Marschner, H. Relation between salt tolerance and long distance transport of sodium and chloride in varius crop species. Australian Journal Plant Physiology, Collingwood, v.5, n.1, p.27-37, 1978.

Malavolta, E.; Vitti, G.C.; Oliveira, S.A. Avaliação do estado nutricional das plantas: Princípios e aplicações. Piracicaba: Associação Brasileira para Pesquisa da Potassa e do Fosfato, 1989. 201p.

Mantovani, A. A method to improve leaf succulence quantification. Brazilian Archives of Biology and Technology, Curitiba, v.42, n.1, p.9-14, 1999.
Marschner, H. Mineral nutrition of higher plants. 2.ed. London: Academy Press, 1995. 889p.

Moya, J.L.; Primo-Millo, E.; Talon, M. Morphological factors determining salt tolerance in citrus seedlings: the shoot to root ratio modulates passive root uptake of chloride ions and their accumulation in leaves. Plant, Cell and Environment, Logan, v.22, n.11, p.1425-1433, 1999.

Munns, R. Comparative physiology of salt and water stress. Plant, Cell and Environment, Logan, v.25, n.2, p.239-250, 2002.

Munns, R.; Termaat, A. Whole-plant responses to salinity. Australian Journal Plant Physiology, Collingwood, v.13, n.1, p.143-160, 1986.

Niu, X.; Bressan, R.; Hasegawa, P.M.; Pardo, J.M. Ion homeostasis in $\mathrm{NaCl}$ stress environment. Plant Physiology, Rockville, v.109, n.3, p.735-742, 1995.

Prisco, J.T. Alguns aspectos da fisiologia do estresse salino. Revista Brasileira Botânica, São Paulo, v.3, n.1/2, p.85-94, 1980.

Salim, M.; Pitman, M.G. Effects of salinity on íon uptake and growth of mung bean plants (Vigna radiata L.). Australian Journal Plant Physiology, Collingwood, v.10, n.4/5, p.395-407, 1983.

Silva, J.V. Efeitos do $\mathrm{CaCl}_{2}$ no crescimento e acumulação de osmorreguladores em plantas de feijão-de-corda Pitiúba estressadas com NaCl. Fortaleza: UFC, 1998, 103p. Dissertação Mestrado

Silva J.V.; Lacerda, C.F.; Costa, P.H.A.; Enéas-Filho, J.; GomesFilho, E.; Prisco, J.T. Physiological responses of $\mathrm{NaCl}$ stressed cowpea plants grown in nutrient solution supplemented with $\mathrm{CaCl}_{2}$. Brazilian Journal Plant Physiology, Campinas, v.15, n.2, p.99-105, 2003.

Storey, R., Salt tolerance, ion relations and the effect of root medium on the response of citrus to salinity. Australian Journal Plant Physiology, Collingwood, v.22, n.1, p.101-114, 1995.

Strogonov, B.P. Physiological basis of salt tolerance of plants. Jerusalem, Israel Program for Scientific Translations, 1964. $279 p$.

Zekri, M. Effects of $\mathrm{NaCl}$ on growth and physiology of sour orange and Cleopatra mandarin seedlings. Scientia Horticulturae, Lexington, v.47, n.3-4, p.305-315, 1991. 